\title{
Somatotype, physical growth, and sexual maturation in young male smokers
}

\author{
K. B. LALL, S. SINGHI, M. GURNANI, P. SINGHI, AND O. P. GARG \\ From the Department of Paediatrics, JLN Medical College and Hospital, Ajmer, India
}

SUMMARY One thousand schoolboys aged 8 to 16 were examined for their somatotype, physical growth, sexual maturation, and smoking habits. Fifty-two boys were found to be smokers, of whom 30 were regularly smoking between two and 20 bidis or cigarettes a day for a mean duration of 2.5 years. The mean height and weight of the smokers was significantly lower than that of the non-smokers at all ages, more so in regular than occasional smokers. Sixty-nine per cent of the smokers had mesomorphic type of body build; about $65 \%$ of the non-smokers had ectomorphic somatotype $(P<0 \cdot 001)$. Onset of puberty occurred significantly earlier among smokers compared with non-smokers, as was evident from the early appearance of genital stage 2, and an early and rapid increase in testicular size. Genital stage 2 appeared at a mean age of 11 years in smokers and 11.6 years in non-smokers. However, the appearance of pubic, axillary, and facial hair was delayed. The possible significance of this is discussed.

Morphological and physical characteristics of adult smokers have been studied. However, little information is available on the body build, height, and weight of young smokers. There is also a paucity of information on the sexual maturation of children who smoke. In the present study we have analysed our findings on the body build, height, weight, and maturation of secondary sex characteristics in young smokers.

\section{Material and methods}

During 1979, 1000 schoolboys of Ajmer city, aged 8-16, were studied for physical growth, sexual maturation, and smoking habits. To obtain a sample representative of all socioeconomic status groups, five schools serving different areas of Ajmer were selected for study. One was a public school serving well-to-do families and one was a school in a slum area; three schools, two Government schools, and one run by a charitable trust served the general population. Between 100 and 150 children were selected in each age group so as to make a sample of 1000 . Before the study was undertaken, headmasters and teachers in these schools were told of its purpose and procedures. Three days before the contemplated day of examination, the boys' parents were requested to fill up a pro forma asking for information about the date of birth of the child, family size, family income, living conditions, and parental literacy. When the children were interviewed, after having established a proper rapport and gaining their confidence, each one was asked about his personal hobbies, ambitions, and smoking habits. The boys were also asked whether they smoked and, if so, what was their frequency of smoking and the age when they started. All those who agreed that they smoked were labelled as smokers, the rest as non-smokers. Those who smoked daily one or more cigarettes or bidis were labelled as regular smokers and those who smoked less than one cigarette or bidi a day as occasional smokers. Ex-smokers, if any, were included in the non-smoker category as there was an apparent reluctance among children to identify with their past smoking habits, and thus it was not possible to obtain reliable information.

A thorough physical examination was carried out, with particular reference to somatotype (type of body build), ${ }^{1}$ height, ${ }^{2}$ and signs of secondary sex characteristics. During the examination for the presence of secondary sex characteristics, care was taken not to affront the dignity of the child. Stages of genital development and growth of pubic, axillary, and facial hair were rated and recorded according to the standard rating of Tanner, ${ }^{3}$ and Neyzi. ${ }^{4}$ Testicular volume was measured by a wooden model of Prader's orchidometer. $^{5}$

Mean height, weight, and testicular volume at different ages were calculated separately for both smokers and non-smokers. The height and weight of smokers was also calculated as a percentage of the mean height and weight of non-smokers of corresponding age. The mean age of appearance of the second stages of various sexual characteristics (genital stage 2 , pubic hair stage 2 , and facial hair stage 2) was calculated separately for smokers and non-smokers.

The statistical significance of the difference between the mean height, weight, testicular volume, and age of appearance of secondary sex 
Table 1 Age distribution of smokers and non-smokers

\begin{tabular}{lrrrrrrrrr}
\hline Age (years) & 8 & 9 & 10 & 11 & 12 & 13 & 14 & 15 & 16 \\
\hline No. of smokers & 1 & 0 & 3 & 2 & 4 & 8 & 10 & 14 & 10 \\
No. of non-smokers & 101 & 106 & 101 & 104 & 104 & 101 & 121 & 96 & 114 \\
\hline
\end{tabular}

characteristics of smokers and non-smokers was determined by Student's $t$ test. The $\chi^{2}$ test was used to discover the statistical significance of the relation between type of body build and smoking habit.

\section{Results}

All the children were homogeneously distributed in various socioeconomic classes when grouped according to the socioeconomic classification of Prasad. ${ }^{\circ}$ Of the 1000 children studied, 52 reported that they smoked. The age distribution of the 52 smokers and the 948 non-smokers is shown in Table 1. Although the youngest smoker previously reported on was aged $3,{ }^{7}$ we found only one child aged between 8 and 9 .

Thirty children in the present study were regular smokers and were smoking between two and 20 cigarettes or bidis a day for a mean duration of 2.5 years. The rest were occasional smokers.

\section{SOMATOTYPES, HEIGHT, AND WEIGHT}

Young smokers differed significantly in body build from non-smokers (Table 2). Most of the smokers (69\%) had a mesomorphic build, whereas most of the non-smokers $(65 \%)$ were ectomorphic $(P<0.001)$. In all age groups, children who smoked were found to be less tall and less heavy than their non-smoking peers. The difference was statistically significant in almost all age groups (Figs. 1 and 2). However, the number of smokers at ages $8,9,10$, and 11 was too small to derive any valid statistical conclusion. The percentage reduction in height and weight was more apparent in regular smokers than in occasional smokers (Fig. 3).

A P P E A R A C E OF SECONDARY SEX CHARA CTERISTICS

The onset of puberty, as made evident by the appearance of genital stage 2, occurred at the significantly younger age of 11 in smokers, compared with 11.6 in non-smokers. None of the smokers were at genital stage 1 at the ages of 10,11 , and 12 ,

Table 2 Type of body build (somatotype) among boy smokers and non-smokers

\begin{tabular}{lll}
\hline $\begin{array}{l}\text { Type of } \\
\text { body build }\end{array}$ & $\begin{array}{l}\text { Non-smokers } \\
(n=948)\end{array}$ & $\begin{array}{l}\text { Smokers } \\
(n=52)\end{array}$ \\
\hline $\begin{array}{l}\text { Ectomorphic } \\
\text { Mesomorphic }\end{array}$ & $615(64.9 \%)$ & $16(30 \cdot 8 \%)$ \\
Endomorphic & $258(27 \cdot 2 \%)$ & $36(69 \cdot 2 \%)$ \\
\hline
\end{tabular}

$x^{2}=42.85 \quad P<0.001$

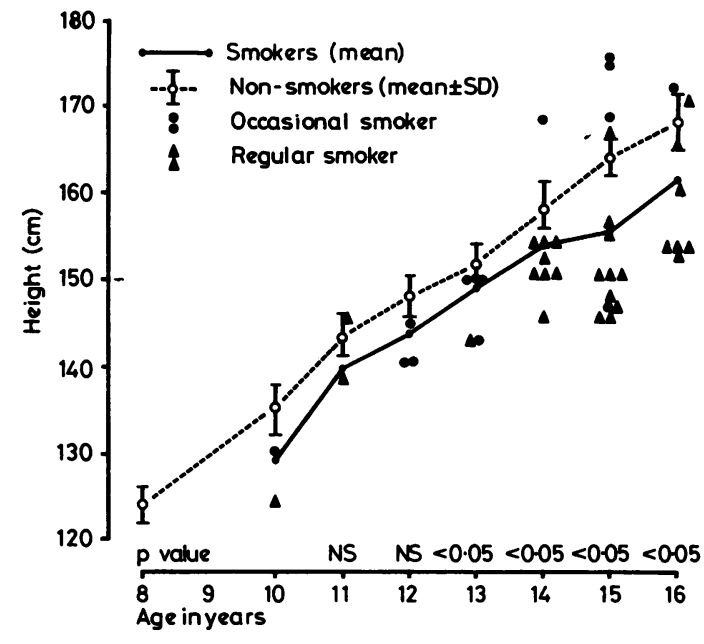

Fig. 1 Height of child smokers and non-smokers. and $\Delta$ represent individual values in occasional and regular smokers.

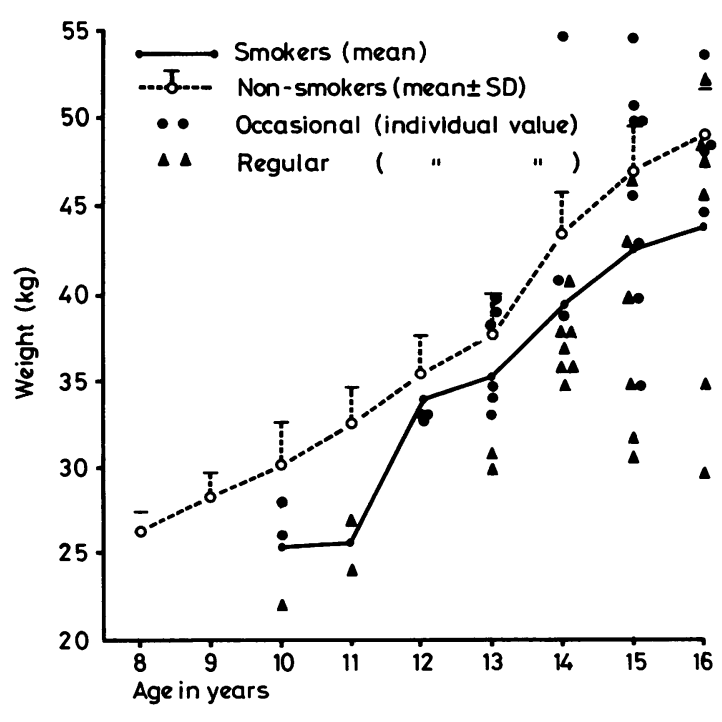

Fig. 2 Weight of child smokers and non-smokers.

$\checkmark$ and $\Delta$ represent individual values in occasional and regular smokers. 
Table 3 Distribution of smokers and non-smokers in genital $(G)$ stages, at different ages

\begin{tabular}{|c|c|c|c|c|c|c|c|c|c|c|c|c|}
\hline \multirow{2}{*}{$\begin{array}{l}\text { Age } \\
\text { (years) }\end{array}$} & \multicolumn{6}{|c|}{ No. of smokers } & \multicolumn{6}{|c|}{ No. of non-smokers } \\
\hline & Total & GI & $G 2$ & G3 & $G 4$ & G5 & Total & $\boldsymbol{G I}$ & $G 2$ & G3 & $G 4$ & GS \\
\hline 10 & 3 & - & 3 & - & - & - & 101 & 21 & 78 & 2 & - & - \\
\hline 11 & 2 & - & 2 & - & - & - & 104 & 6 & 38 & 60 & - & - \\
\hline 12 & 4 & - & 2 & 2 & - & - & 104 & 5 & 38 & 61 & - & - \\
\hline 13 & 8 & - & - & 5 & 3 & - & 101 & - & 34 & 48 & 19 & - \\
\hline 14 & 10 & - & - & 2 & 7 & 1 & 121 & - & 19 & 46 & 52 & 4 \\
\hline 15 & 14 & - & - & 2 & 9 & 3 & 96 & - & 5 & 24 & 49 & 18 \\
\hline 16 & 10 & - & - & - & 3 & 7 & 114 & - & - & 5 & 26 & 83 \\
\hline
\end{tabular}

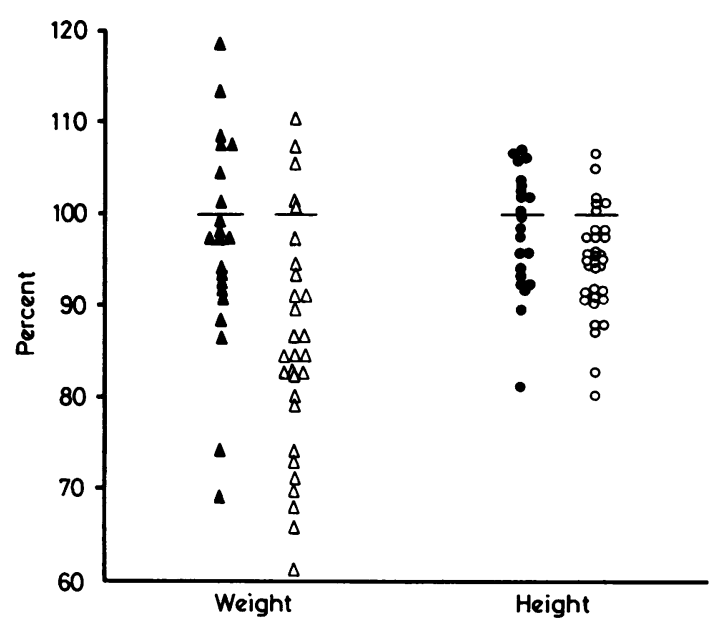

Fig. 3 Weight and height of child smokers expressed as percentage of mean weight and height of non-smokers of corresponding age.

$\Delta$ and $\mathrm{O}$ represent individual values in occasional smokers, and $\Delta$ and $O$ represent regular smokers.

whereas $20 \%, 6 \%$, and $5 \%$ respectively of non-smokers at these ages were still at genital stage 1 . Similarly, none of the smokers at ages 13,14 , and 15 were at genital stage 2 , whereas about $34 \%, 16 \%$, and $5 \%$ respectively of non-smokers at these ages were still at that stage (Table 3 ). There was a rapid increase in testicular size among smokers, as suggested by significantly higher testicular volume among them at ages 13, 14, 15 and 16 (Fig. 4). In contrast, the second stages of growth of pubic, axillary, and facial hair appeared at a significantly later age among the smokers compared with the non-smokers (Table 4).

\section{Discussion}

The smoking habit of an individual is considerably influenced by his genotype. ${ }^{8}$ Because a person's phenotype is an expression of his genotype, we correlated adoption of smoking habit with morphological characteristics. We found that more than two-thirds of smokers had mesomorphic type of body build. This substantiates the assumption that
Table 4 Age of appearance of second stages of genital (G2), pubic hair (PH2), axillary hair (A2), and facial hair (F2) in young smokers compared with non-smokers

\begin{tabular}{llll}
\hline & \multicolumn{2}{l}{ Age of appearance } & \\
\cline { 2 - 3 } Stage & Smokers & Non-smokers & $P$ \\
\hline G2 & $\begin{array}{lll}11.0 \pm 0.9 \\
(n=7)\end{array}$ & $\begin{array}{l}11.6 \pm 0.11 \\
(n=212)\end{array}$ & $<0.05$ \\
PH2 & $\begin{array}{l}12.8 \pm 1.4 \\
(n=12)\end{array}$ & $\begin{array}{l}11.8 \pm 1.1 \\
(n=242)\end{array}$ & $<0.05$ \\
F2 & $14.5 \pm 0.80$ & $\begin{array}{l}13.6 \pm 1.04 \\
(n=327)\end{array}$ & $<0.01$ \\
A2 & $(n=19)$ & $\begin{array}{l}13.2 \pm 0.8 \\
(n=254)\end{array}$ & $<0.05$ \\
\hline
\end{tabular}

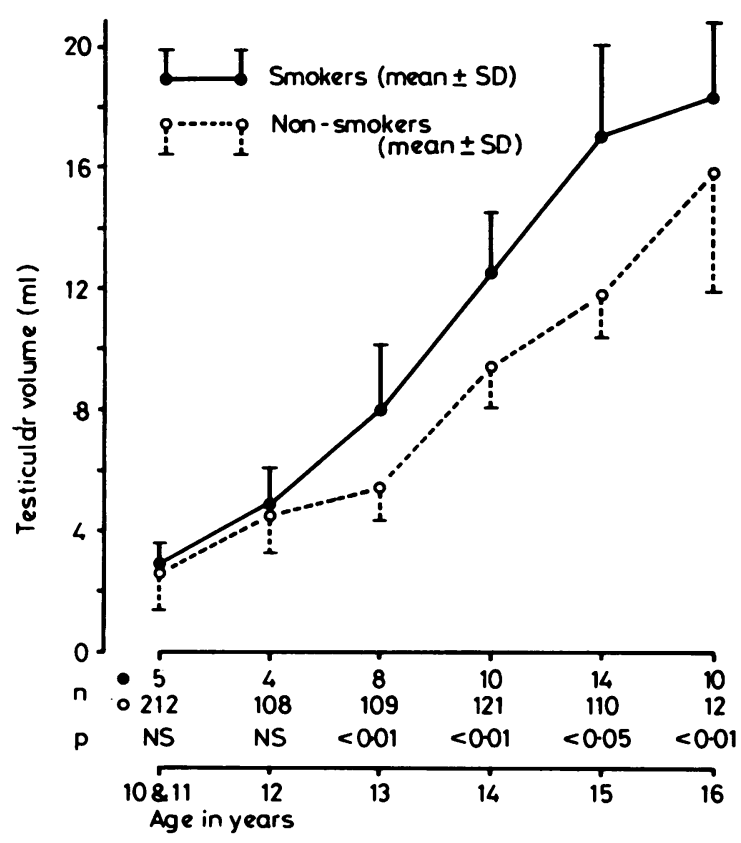

Fig. 4 Testicular volume among smokers and non-smokers. 
the smoking habit of an individual is in part a reflection of his biological or genetic makeup.?

We found that children who smoked were significantly lighter and shorter than their non-smoking peers. This is in agreement with observations made on adult smokers. ${ }^{9-13}$ The reduction in weight and height in the young smokers may have been analogous to the intrauterine growth retardation seen among the infants of mothers who smoke, as regular smokers were much shorter and lighter than occasional smokers. The exact mechanism which leads to growth retardation in smokers needs to be studied. Could it be due to inadequate supply of nutrients to tissues, hypoxia secondary to persistent carboxyhaemoglobinemia, and sluggish circulation due to increased viscosity and decreased plasma volume of the blood? ${ }^{13}$

The early onset of puberty in the young smokers, as was made evident by the early appearance of genital stage 2 , is the most significant observation of this study. Surprisingly, further maturation of secondary sex characteristics in these smokers was delayed, as was made evident by later appearance of the second stages of pubic, axillary, and facial hair. It would be interesting to know whether this was the cause or the effect of smoking. Could it be that because of early onset of puberty, these boys take up smoking to assert their masculinity and to show off 'adolescent's independence'? ${ }^{14}$ Or is it that smoking is a manifestation of behavioural changes ${ }^{15}$ produced by a sudden spurt in circulating androgen levels in association with early onset of puberty? The rapid increase in testicular volume over the age of 12 seen in this study remains inexplicable.

Persky et $\mathrm{al}^{16}$ showed that smoking causes a fall in the serum testosterone level in alcoholics. The increased testicular size in boy smokers may therefore be a sort of compensatory hypertrophy. This reduction in serum testosterone levels following adoption of the smoking habit may also explain the delayed appearance of secondary sex characteristics related to the growth of pubic, axillary, and facial hair, because a certain level of androgen is required for the transformation of vellus hair into the terminal hair. ${ }^{16}$ It may be worthwhile to carry out similar studies in children of other ethnic groups to see if they are similarly affected. We also suggest that endocrinological work be undertaken to explain the biochemical basis of these changes.

Reprints from Professor K. B. Lall, Department of Paediatrics and Neonatology, JLN Medical College, Ajmer, Rajasthan, India.

\section{References}

${ }^{1}$ Sheldon WH. Varieties of Human Physique. New York: Harper, 1940.

${ }^{2}$ Indian Council of Medical Research. Growth and Physical Development of Indian Infants and Children. Technical Report Series No. 18, 1972.

${ }^{3}$ Tanner JM. Growth at Adolescence. 2nd edn. Oxford: Blackwell Scientific Publications, 1962.

${ }^{4}$ Neyzi O. Puberty in children of different populations and of different socioeconomic background. In: Newer Horizons in Tropical Pediatrics. Suraj Gupe, ed. Delhi: Jaypee Brothers, 1977: 25-44.

${ }^{5}$ Prader A, Haflinger $H$, Kind HP, Zachmann $M$. Testicular volume-cross sectional and longitudenal results, quoted by Marshall WA and Tanner M. In: Davies JA, Dobbing J, ed. Scientific Foundations of Paediatrics. London: William Heinemann, 1974: 124-51.

${ }^{6}$ Prasad. BG. Changes proposed in social classification of Indian families. J Indian Med Assoc 1970; 55: 196-200.

${ }^{7}$ Lall KB, Barar FSK, Pandsey SK. Probable tobacco addiction in a 3-year-old child. Clin Pediatr 1980; 19: 56-61.

${ }^{8}$ Fisher RA. Cancer and smoking. Nature 1958; 182: 596.

${ }^{9}$ Seltzer CC. Morphologic construction and smoking. JAMA 1963; 183: 639-45.

${ }^{10}$ Ashfor JR, Brown S, Duffield, Smith CS, Fay JWJ. The relation between smoking habits and physique, respiratory symptoms, ventilatory functions and radiological pneumoconiosis amongst coal workers at the Scottish collieries. Br J Prev Soc Med 1961; 15: 106-16.

${ }^{11}$ Higgins MW, Kjelsber M. Characteristics of smokers in Tecumach, Michigan. II; The distribution of selected physical measurements and physiologic variables and the prevalence of certain diseases in smokers and non-smokers. Am J Epidemiol 1967; 86: 60-77.

${ }^{12}$ Khosla T, Lowe CR. Obesity and smoking habits. Br Med $J$ 1971; iv: $10-13$.

${ }^{13}$ Smith JR, Landow SA. Smoker's polycythemia. $N$ Engl J Med 1978; 298: 6-10.

${ }^{14}$ Bewley BR, Bland JM, Harris R. Factors associated with start of cigarette smoking by primary school children. $\mathrm{Br}$ J Prev Soc Med 1974; 28: 37-44.

${ }^{15}$ Brook RV. Androgens. Clin Endocrinol 1975; 4: 503-20.

${ }^{16}$ Persky H, O'Brien CP, Fine E, Howard WJ, Khan MA, Beck RW. The effect of alcohol and smoking on testosterone function and depression in chronic alcoholics. Am J Psychiatr 1977; 134: 621-7. 